\title{
Investigating the Common Errors Among Basic Level Schools Pupils on Writing Composition
}

\author{
Nahid Alamin Ibrahim \\ Languages Department, Port Sudan Ahlia College, Port Sudan, Sudan \\ Email address: \\ nahidibrahim7272@gmail.com \\ To cite this article: \\ Nahid Alamin Ibrahim. Investigating the Common Errors Among Basic Level Schools Pupils on Writing Composition. American Journal of \\ Information Science and Technology. Vol. 3, No. 2, 2019, pp. 35-40. doi: 10.11648/j.ajist.20190302.11
}

Received: February 26, 2019; Accepted: April 15, 2019; Published: June 25, 2019

\begin{abstract}
This study aimed to analyze pupils' error in composition writing in south of Khartoum locality in Alshagra basic level schools for boys and girls grade eight in Sudan. It is also aimed to identify the factors that cause this weakness in English language. The descriptive analytical approach was used to collect and analysis the data. Teachers in Alshagra basic schools South of Khartoum locality participate in completing the questionnaire, to express their opinions towards the suggested ideas. The researcher also used written interview that involved four questions. In writing composition it's observed that punctuation marks cause problems for pupils and this leads to misunderstand so these errors are common among the pupils. Other mistakes are commonly committed. The researcher recommended that: 1-The English teachers should be given training courses on the methodology of teaching writing skill. 2-Teachers should devote enough time and effort when dealing with the numerous stages of the writing process. The most important Findings are: 1-Teaching writing specifically teaching composition writing is more complicated and need more efforts than other skills of language. 2-Mother tongue interference is the one of the most problems that faces students in writing composition.
\end{abstract}

Keywords: Ahlia College, Errors Analysis, Composition Teaching, Writing, Schools, Materials

\section{Introduction}

Errors making as emphasized by Robinson (1998) is a natural phenomenon in learning, so why students insist on committing the Same errors even when such errors have been repeatedly pointed out to them. What is questioned by language teachers yet not all errors are the same, sometimes they seem to be deeply in grained. But teachers return this problem to the difficulty of writing skill in the pupils' point of view .pupils like other skills more than writing. Writing has become difficult task but it is important skill in developing the students' competence in learning strategy, even native English speakers are making errors. Writing is a complicated process difficult for the students to acquire, practice and write into intelligible comprehensible piece of writing.

\subsection{Statement of the Problem}

Pupils commit different kinds of errors. Some of these errors occur because they are made in natural way and not recognized easily. Since they look like the right usage of language. They are passed from learner to another learner sometimes among the community members. Therefore the common errors aren't eliminated immediately by learners themselves or others. In writing composition it's observed that some punctuation marks cause problems to basic level schools pupils, the way that caused misunderstanding of these errors and they become common. Other mistakes are commonly committed. In writing composition identifying these errors makes it easy for teachers and pupils to spot them also conscious attempts can solve some problems.

\subsection{Significance of the Study}

The current study no doubt is useful in broadening our knowledge about errors in general and actual commonly committed mistakes in writing composition within basic level schools pupils, therefore the present study is significant for English language teachers to be aware of the common errors and to deal with them with suitable emphasis to avoid the consequences of these errors.. Moreover it is useful for pupils and language learners in general to learn about common 
errors and try to avoid them. Beside that a large number of graduated students or researchers or teachers who are involved in the process of teaching and learning process can benefit.

\subsection{Objectives of the Study}

The current study aims at identifying the common errors committed by basic level schools pupils on their attempt to write composition. It also aims at carrying out the causes of errors and the main types of these errors. The present study attempt to find remedies for these errors.

\subsection{Questions of the Study}

What are the common errors of witting composition among basic level schools pupils in Alshagra basic level schools in Khartoum locality?

What are the majority common errors in writing composition that occur among these pupils?

How do we reduce and avoid such errors?.

\subsection{Hypothesis of the Study}

The researcher hypothesize that basic level schools pupils encounter commit errors in writing composition, due to grammar syntax, semantics, spelling and mother tongue interference.

To reduce the serious errors in writing composition among basic level schools pupils, the researcher suggests to follow up the effective use of teaching methods and effective learning processes

\subsection{Limitation of the Study}

This study is confined to the common errors committed by the pupils of eighth class in composition writing in Alshagra Basic schools pupils for boys and girls at Khartoum State in Sudan. The duration of academic year 2015-2016.

\subsection{Methodology of the Study}

This study adopts the descriptive and analytical approach. Concerning tools of data collection, the researcher designed a test targeting basic level pupils, eighth class a questionnaire targeting English language teachers, an interview with heading English language inspector teachers, English language retired teachers and English language experts.

\subsection{Definition of Key Terms}

Errors in this study the researcher uses the word error to refer to both errors and mistakes.

Error analyses theories and discussions on the discipline of SLA about the deviant use of a learners to a certain language item.

Writing as defined by the educationalist in terms of the skill and means of expression of ideas.

Composition is any writing of students as part of learning or assessment work under tutors.

\section{Methods}

This chapter presents the design of the study, description of the study are, sample and sampling techniques, data gathering instruments and data collection procedures.

Design of the study

Descriptive case study research method was employed in this study to assess students writing composition especially grade eight Basic school pupils in Alshagra Basic level schools pupils for boys and girls, using questionnaire and written interview that contain open-ended questions According to Kumar (1996), descriptive methods attempt to describe systematically a situation, problem or phenomenon. Therefore the researcher used descriptive research method since it's important in gathering data in human activities.

\section{Data Collection Instruments}

This study was conducted in South of Khartoum locality. Alshagra basic schools for boys and girls (eighth class) pupils were chosen for this study because the researcher works as a teacher of these schools for a long time, so the researcher could notice these problems.

\subsection{Participants}

The sample and the population of the study were the Basic level school pupils in. Alshagra basic schools with a population of fifty teachers, the researcher has chosen a sample of forty teachers randomly

\subsection{Tools}

This study employed two different data gathering instruments; a questionnaire and a written interview that contain open-ended question. The questionnaire was the major instrument, while the written interview was used as a supportive data gathering instrument.

\subsection{Questionnaire}

The researcher has constricted in order to gather data from basic level teachers. Forty English language teachers were participated in Alshagra basic schools in the academic year 2015 - 2016 The questioning was used to obtain rich information regarding pupils' common errors on writing composition. The questionnaire is divided into two parts: part one included personal information of subjects. In this part quantitative approach used in collecting data to identify factors that significantly contributed occurrence of common errors on writing composition. This part includes school name, the degree of the teacher and the experience of the teacher. Part two is divided into three sections related to research that aims at answering some issues described in the theoretical part in order to get necessary results and data. The first dimension is about the existences of common errors and composed of three items. The second dimension is about items related to the pupils and writing composition and includes eleven items. The third dimension ns is the role of 
teacher or points trying teaching methods and remedy sixties. Each of the twenty items has statement's with five alternatives, each choice represented a range from which subjects could choose and tick (/) in the most appropriate responses.

This questionnaire includes questions which aimed at investigating the views of the teachers towards the common errors on writing composition.

\subsection{Tools of Data Collection}

This study employed two different data gathering instruments; a questionnaire and a written interview that contain open-ended question. The questionnaire was the major instrument, while the written interview was used as a supportive data gathering instrument This part gives detailed description to the procedures taken to collect data the questionnaire and the written interview. The researcher distributed the questionnaire among forty English language teachers in Alshagra basic schools in South of Khartoum locality. The subjects were instructed to respond by selecting a choice in appropriate box. This requires subjects to choose only one of the four choices; strongly agree- agree - strongly disagree- disagree, which are given to express their opinions towards the suggested ideas.

The researcher also used written interview that involved four questions. Then ten expert teachers answered these questions.

\subsection{Validity and. Reliability of the Questionnaire}

In order to ensure the validity and reliability of the questionnaire is checked and examined by three figures who are university lectures with experience in this field. The researcher made modifications which they have high consideration. Beside this, they presented more important advice for designing and constructing the appropriate items.

\subsection{The Written Interview}

A written interview is used as another tool of collecting data. This contain open - ended questionnaire. It presented to ten very experts in English language teaching. It consists of four questions in which respondents have to answer the questions using their own words to express own their ideas and opinions. Gillham (2000) views that open ended question is best used when the answer is open. The open- ended questions were designed with the purpose of yielding qualitative data through the text responses written in the respondents' own words (Jackson and Trochim (2002).

\section{Results and Discussion}

In this chapter the researcher analyzed the data obtained from the teachers' questionnaire as well as forms the written interview. Started by the questionnaire analyses followed by the interview.

\subsection{The Data of the Questionnaire}

The questionnaire was given to forty respondents who represent the teachers in Alshagra basic level schools in South of Khartoum locality.

\subsection{Analysis and Discussion of the Questionnaire}

The questionnaire has been given to the English language teachers in Alshagra basic schools, South of Khartoum locality. It was handed to the teachers, then collected from the teachers after being responded by them and analyzed. The findings were discussed according to the hypothesis of the study.

Respondents are post graduate; this proves that most respondents are qualified.

Table 1. Pupils commit common errors in vocabulary for world choice.

\begin{tabular}{llll}
\hline Strongly agree & Agree & disagree & Strongly disagree \\
\hline $30 \% 12$ & $65 \% 26$ & $\% 52$ & $0-$ \\
\hline
\end{tabular}

The above table indicates that the data analysis of the questionnaires approve with majority of teachers $65 \%$ said the pupils commit common errors in vocabulary for word choice so the first statement of questionnaire is approved according to above result.

Table 2. Spelling errors are common in composition writing

\begin{tabular}{llll}
\hline Strongly agree & Agree & disagree & Strongly disagree \\
\hline $56.5 \% 23$ & $32.5 \% 13$ & $10 \% 4$ & 0 - \\
\hline
\end{tabular}

According to above result the state mentis accepted the main findings indicate that analysis of the questionnaires approved with majority of teachers strongly agree $5705 \%$ that spelling errors are common in composition writing.

Table 3. The common errors made by students in composition wanting due to spelling, punctuation and sentences structure.

\begin{tabular}{llll}
\hline Strongly agree & Agree & Disagree & Strongly disagree \\
\hline $47.5 \% 19$ & $45.5 \% 18$ & $7.5 \% 3$ & $0 \%$ \\
\hline
\end{tabular}

The above table shows that the data analysis of questionnaire approved with majority of teachers strongly agree $47.5 \%$ the common made by students in composition writing due to spelling, punctuation, sentences structure and sequence of ideas.

Table 4. pupils fearful of composition writing because of the errors they commit.

\begin{tabular}{llll}
\hline Strongly agree & Agree & Disagree & Strongly disagree \\
\hline $55 \% 22$ & $17.5 \% 7$ & $7.5 \% 3$ & $20 \% 8$ \\
\hline
\end{tabular}


that strongly agree 55\%pupils fearful of composition writing because of the errors they commit.

Table 5. pupils are unable to use loan words.

\begin{tabular}{llll}
\hline Strongly agree & Agree & disagree & Strongly disagree \\
\hline $32.5 \% 13$ & $40 \% 16$ & $7.5 \% 3$ & $20 \% 8$ \\
\hline
\end{tabular}

The above figure shows main the statement of questionnaire is accepted, the main findings refer that the data analysis of questionnaire as assert with majority of teaches agree $40 \%$ pupils are unable to use loan words

Table 6. Manipulation of the script hand writing.

\begin{tabular}{llll}
\hline Strongly agree & Agree & disagree & Strongly disagree \\
\hline $32.5 \% 13$ & $42 \% 17$ & $5 \% 2$ & $20 \% 8$ \\
\hline
\end{tabular}

It seems from table that the sixth statement of questionnaire is stated the main findings reflect that the data analysis of the questionnaire assert with 42.5010 teachers said agree. Pupils are unable to manipulate the script hand writing.

Table 7. Composition writing is task which disturbs pupils.

\begin{tabular}{llll}
\hline Strongly agree & Agree & disagree & Strongly disagree \\
\hline $45 \% 18$ & $30 \% 12$ & $0 \%$ & $25 \% 10$ \\
\hline
\end{tabular}

In the light of the result above the statement (7) of questionnaire is accepted. since findings indicate that the data analysis of the questionnaire confirm which majority of teachers noticed that strongly agree $45 \%$ Composition writing is task which disturb pupils.

Table 8. Pupils face difficulties specially in using correct tenses.

\begin{tabular}{llll}
\hline Strongly agree & Agree & disagree & Strongly disagree \\
\hline $50 \% 20$ & $21 \% 11$ & $0 \%$ & $22 \% 5$ \\
\hline
\end{tabular}

In the light of the result above she statement (8) of questionnaire is accepted, since findings refers that the data analysis of the questionnaire emphasized confirm with majority of teachers noticed that strongly agree 50\%. Pupils face difficulties specially in using correct tenses

Table 9. Pupils don't master the rules of punctuation.

\begin{tabular}{llll}
\hline Strongly agree & Agree & disagree & Strongly disagree \\
\hline $46.5 \% 19$ & $35 \% 14$ & $2.5 \% 1$ & $15 \% 6$ \\
\hline
\end{tabular}

It is clear that the statement (9) of questionnaire is accepted. Since main findings explain that the data analysis of questionnaire accepted with majority of teachers noticed that strongly agree $47.5 \%$. Pupils don't master the rules of punctuation.

Table 10. Pupils are unable to convey their own ideas when they write composition.

\begin{tabular}{llll}
\hline Strongly agree & Agree & disagree & Strongly disagree \\
\hline $32.5 \% 13$ & $47.5 \% 19$ & $7.5 \% 3$ & $12.5 \%$ \\
\hline
\end{tabular}

It is clear that, the statement (10) of questionnaire is accepted. since main findings explore that the data analysis of questionnaire accepted with majesty of teachers noticed that agree $4.5 \%$. Pupils are unable to convey their own ideas when they write composition.

\subsection{Analysis of the Interview}

In this section the researcher will analyze the data obtained from the expert teachers about written interview (open-ended question).

Statement 1; are there any common errors on writing composition? if so, please mention them.

In answering this question all teachers agreed and confirmed that the most common errors are letters formation, capitalization, spelling errors, punctuation errors, grammatical errors, incorrect ordering of ideas, misusing using of helping points lack of vocabulary and they not dealing with sentence structure while other teachers added things done by pupils lead to common errors like misunderstanding of the title on the other hand, others said that they make errors when they try to introduce and the topic. Beside this, others teachers refers to that some teachers don't use scientific ways of when they teach them composition writing. others explained that pupils generally hate writing composition.

Statement 2: what causes these common errors and how do they occur?

All teachers agreed that the most reasons are mother tongue interference although, some teachers are trained but, are not qualified. in the same way, teachers don't care about writing skill. similarly, there is very less periods on spelling and dictation. as a result of not training for writing in the early stage so, they made errors. Consequently they made errors because they don't learn punctuation rules. they have lack of vocabulary for this reason they made errors. however, if they practice more writing pupils will make very less errors but, they don't practice writing. hence, writing is the most difficult skills they make errors pupils suffer from ordering ideas thus, they make errors. They are not able to use grammar therefore, pupils make errors. while others added that in fact pupils make errors because of some teachers don't use effective teaching method of writing. first, some teachers teach in Arabic. second, they teach only for duty and third, others they give less encouragement for their pupils. to clarify that, most pupils have a view against but, believe that English is not important indeed, pupils make errors for instance, they hate English moreover, they don't know what the examiner does he /she want. pupils namely, have in sufficient activities in writing it fallows that lack of following up pupils writing performance. thus, pupils have of literatim periods. Equally, pupils commit errors because of comparing English composition and Arabic composition. Since, pupils come from different culture they make errors. Furthermore, they don't use the techniques and steps of writing this suggests that, pupils make errors. On the contrary, they don't do their homework. typically, some pupils fear from making errors when they are writing. further, they have shortage of 
spoken language no practice for this type of language they also commit common errors because of, weakness of teachers

Statement 3: In your Opinion what do you think the solutions for problems?

All teachers agreed that there must be more concentration on teacher training. They also argued that spelling periods must be done at least one period in each week in order to increase their vocabulary. In order to, cure the problems, sot teacher carry out on composition writing. For this reason, teaching grammar in details is very important. of course, teachers must care about pupils handwriting form early stage. In spite of, using traditional methods on teaching teachers should adopt new and live methods, all of them believed that, hand writing must be the main pillar in teaching writing. they admit, that teaching pupils rules of punctuation will involve in solving writing problems. all of them think that practice of writing is necessary to solve the problem. others argued that their parents must participate. In addition, it is being very nice if the teachers teaching through culture. Another thing that teachers need to follow up the performance of pupils in writing composition. Undoubtedly, word formatting is very necessary in order to, make the correct statement. It is obviously, the system of training teachers is theoretical. Where as much model periods will gain excellent results if the training is being practical. As well as, the teachers ought to train their pupils to correct their errors so, they will decrease them then they learn from their mistake and assess their work. Other teachers claim that, Curriculum must contain literature. First, this will increase vocabulary (words). Second, literatures lead them to enjoy and love English.. Others teachers asked to return to pervious curriculum which contains readers from one to seven because of rich vocabulary.

Statement 4: what is your recommendation in order to avoid and reduce these errors?

All teachers agreed that they must be smooth in teaching English. The teachers for example, sometimes present, joke and do entertainment so, pupil love language. They also agreed teachers focus on teaching basic techniques' of composition writing such as, thinking prewriting, writing...etc.

Others suggest that, give the pupils different kinds of topics from their environment similarity and it is better if the teacher begins with guide composition. Others explain that, crowded classes will make the education operation difficult for this reason; they suggest the class must be less than forty. Also teacher ought to give them self-confidence. In addition, pupils make list of words new words and their meaning therefore, to know their function then put in sentence. In order to make English enjoyable clearly, it is better they read very simple stories book. Generally communication is very important, for instance, if they have chance to talk; intensively, this will assist fluency and accuracy. Others said that the marking which is done by the teacher must be followed line by line not at the end o paper Others suggest that, each pupils must be given book not sharing with another pupil thus, will help them to do homework.

Statement 5: Do you have any comments.
Here each teacher said from his view in other work each teacher suggests:

Teacher claim the teacher must be patient to the pupils especially, when they are writing. On the other hand, another advice to use traditional method then they teach letters such as, using pieces of papers, gum and and. another teacher a advices, teachers to use media which includes internet, computer, overhead project.. etc. this importantly facilities learning process. Another teacher claim that there are lack resources in particularly this has bad affection. For this reason there must be more and more resource

Teacher who teach more than two classes suffer as a result of this he / she will not able to follow them. another teacher applicant that teacher must develop himself consequently, this will make him contemporary and reflex very good results. Another teacher required that cancel multiple choice for example a, b, c, or d because of very less effort which is done form the pupils.

\section{Findings and Recommendations}

This chapter presents brief summary of the study with its aims and findings, then the pedagogical implications of the study are discussed and recommend - notion of how to improve, composition writing. Finally asset of suggestions have been presented for further research.

Teaching writing specifically teaching composition writing is more complicated and need more efforts than other skills of language. 2. Mother tongue interference is the one of the most problems that faces students in writing composition. 3 . The investigation shows that is deteriorating basic school due to some factors which affects the teacher's performance and the student's ability. Also the following recommendation can be forwarded. 4. Regular training programmers should be set to train English language teachers 5. An English language teacher should be good model of the target language. A. teachers should motivate students to practice o raise their B. A in English language teacher should be a good model of the target language. teachers must use different in teaching writing that according to level of their students. D -The English teachers should be given training courses on the methodology of teaching writing skill. E.-The process approach to teaching writing should be generalized and adopted by the teachers. In other words, teachers should be sufficiently trained.

\section{References}

[1] Amin. M. Ahmed, (2006). Astrategy for teaching Guided Free Composition in Sudanese Secondary Schools. Unpublished PH. D. Disser- talion.

[2] Brown, H. D (2000). Principle of Language Learning and teaching. Newyork, Longman.

[3] Brown, H. Doyglas. (2001). teaching by principle: Anlmperative Approach to Language Pedagogy, $2^{\text {nd }}$ Ed New work: Addison Wesley Longman Inc. (p335). 
[4] Brumfit, C. J, and Johnson; K (1991). The Communicative approach to language Teaching. Oxford: Oxford University Press.

[5] Chan. Y. w. (2004). Syntactic transfer: evidence from the interlanguage of Hong Kong Chinese ESL Learners. The modern Language Journal. 88 (1): 56-74.

[6] Chaouh Mekki, 2011/2012. The Student awareness of Writing Skill. Biskra University.

[7] Chiang, P. J. (1993). How improve English comp. osition teaching in Taiwan's high Schools: Study of error types and learning Strategies. Master Thesis, National Kaohsiung Normal University.

[8] Dornyei, Z. 2003. Questionnaire in second Language Research: Construction, Administration and processing. London: Lawrence. Erlbaum Associate, Inc.

[9] Erdogen. v (2005). Contribution of error analysis to foreign Language Teaching. Mersin University Journal of the Facility of Education

[10] Fujied, y (Mars, 2006). Abrief historical sketch of second Language Writing Studies: Retrospective. Retrieved Ivaly, 2009 form http://www.Kyoai.Jp/College /ronshuu/noob/fujieda pdf.

[11] Gillham, B. (2000). Developing a questionnaire. Newyork. Ny: Continuum.

[12] (Gillespie and Graham, 2014; Graham et al 2012; Graham and Perin, 2007).
[13] Huang. S. J. (2006). Acase Study of EFL Students' Writing errors on a wab - based writing program. The proceedings of 2006 International Conference and work Shop on TEFL and Applied Linguistics. PP. 139-146 MingChuan University.

[14] Huang, S. L (2001). Error analysis and Teaching Composition. Master Thesis. National Sting Hua University.

[15] Hyland, K. (2003). Second Language Writing Cambridge University Press. Http://enl.Wikipedia. org/wiki/Awareness.

[16] Laith Nasser Hassan, (2013). Basic School Students (with Reference to the bth Grade In Writing English Language. Unpublished master's thesis Red Sea University.

[17] Mohammed Amin Hussen, (2015). Assessing Students' Paragraph Writing Problems. Haramaya Univerity. Atheopia

[18] Nemouchi, A. (2008). Writing Connection with Grammar and Literature in the study organization of the LMD System at the University of Constantine. Unpublished PHD dissertation University of Constantine.

[19] Pinar Karahan, (2011). Analysis of syntactic Error in the Composition of the students Taking. The Proficiency Exam At ELT Department Pamukkale University.

[20] Sanal F (2007). A learner Based Study on second Language Lexicology of Turkish Students of English, Doctoral Thesis, Cukuova University.

[21] Punctuation marks Where need" $\{$ on line $\}$ www.mhbe. Com. 